\title{
Barriers to access maternal health services among urban poor women in Bangladesh: A Case of Rajshahi City
}

\author{
Bijoy Krishna Banik ${ }^{1}$, Md. Saidur Rashid Sumon ${ }^{2}$
}

${ }^{1}$ Professor of Sociology, University of Rajshahi, Rajshahi, Bangladesh. ${ }^{2}$ Assistant Professor of Sociology, Jagannath University, Dhaka, Bangladesh.

\begin{abstract}
Bangladesh has made tremendous achievements in the health sector over the last few decades, albeit worse in maternal health $(\mathrm{MH})$ compared to other South Asian countries. The fact that women, particularly poor, have less access to maternal health care (MHC) services is one of the prime reasons. The main objective of this study was to explore what types of barriers poor mothers faced during the service use. A triangulation of method (interviews of service recipients through interview schedule and service providers through checklist, focus group discussion and observation) was used for the collection of primary data (sample 200) from two slum areas in Rajshahi City between March and April, 2013. The study found socio-cultural and organizational barriers to access to MHC services more acute than physical and financial barriers. As suggested, building awareness of bad consequences of early marriage on $\mathrm{MH}$, ensuring a strong coordination among service providing organizations in dispensing free drugs and posting female doctors in study areas are urgently needed for further improvement of $\mathrm{MH}$.
\end{abstract}

Keywords: Barriers, Maternal healthcare services, Urban poor women, Rajshahi City Corporation, Bangladesh.

\section{Introduction}

Bangladesh has made tremendous achievements in the health sector over the last few decades. ${ }^{1-2}$ The population growth rate has come down from 3 in 1975 to $1.58 \%$ in 2015 , the fertility rate has declined from 6 to 2.55 , the contraceptive prevalence rate rose to 56 from $7.7 \%$ in 1975, the infant mortality rate has come down to 48 from more than a 100 per 1,000 . There was an increase of six years in the life expectancy between 2007 (64 years) and 2012 (70 years). Of course, there are many negative statistics in the health sector. The family planning program is not expanding, rather stalling ${ }^{3-4}$ and about 15,000 mothers die annually at the time of delivery $(2.4$ maternal deaths per thousand) and 7000 infants die every year. About $70 \%$ of pregnant women suffer from anaemia, $71 \%$ of deliveries take place at home and $45 \%$ of babies are born under-weight. ${ }^{5-9}$

One of the main reasons, as indicated by anecdotal evidence, for worse situation in maternal health $(\mathrm{MH})$ is that women, particularly poor, have less access to healthcare services. In addition, a lot of research ${ }^{10-22}$ found class and region-based inequity in access to primary, particularly maternal, healthcare services and broadly classified all access barriers into four sections; socio-cultural, financial, physical and organizational/ institutional.

This research therefore intended to deal with the issue of maternal health care (MHC) services, provided by different organizations in Rajshahi City. Exploring different barriers poor mothers faced during the service use is an urgent requirement of the hour. How did urban poor women experience this service? Did they have access to

\section{Practice Points}

- Maternal health $(\mathrm{MH})$ situation in Bangladesh was worse compared to other South Asian countries.

- Maternal mortality rate in Rajshahi region was more than that in other regions in Bangladesh.

- Socio-cultural and organizational barriers are more keen than physical and financial barriers in study areas.

- Sensitizing community about adverse consequences of early marriage on $\mathrm{MH}$ is urgent.

- Proper coordination and distribution of healthcare services of different organizations is one of the best ways of improving MH situation.

MHC services and affordability to pay the service charges and receive good quality of service? These questions demand investigation. Broadly speaking, the main aim of the study was therefore to examine different barriers that discouraged women from going for MHC services.

The next section highlights research techniques adopted in this study which is followed by the discussion of results of the study. The penultimate section highlights main findings of the study while conclusion and recommendations are made in final section.

Correspondence: Dr. Bijoy Krishna Banik, Professor of Sociology, University of Rajshahi, Rajshahi, Bangladesh. E-mail: bkbanik2001@yahoo.com. 


\section{Materials and methods}

Mixed methods were used for collecting primary data. They include interviews of service recipients through interview schedule and service providers through checklist, focus group discussion (FGD) and observation. The main reasons for choosing mixed methods were to understand and interpret the problems, to explore the barriers to health care, and to watch conditions of poor women from their situations as well as to mitigate methodological problems of validity and bias. ${ }^{23-24}$

The study was conducted by using multi-stage sampling technique which included purposive for site selection, systematic random sampling for household selection and finally snowball sampling for respondent selection.

\section{Area Selection}

The main focus of the study was to highlight access barriers of poor women to MHC services in urban areas. In this regard, out of seven divisional regions in Bangladesh, Rajshahi region was selected due to its worst condition. The following figures suggested that Rajshahi situation was not better compared to other regions in Bangladesh.

- MH situation in Rajshahi division was worse than other divisions in Bangladesh. The maternal mortality rate in Rajshahi and Bogra regions within Rajshahi division was 2.9 and 3.0 respectively while the figure for Barisal, Pabna, Tangail and Dinajpur was 2.6, 2.6, 2.6 and 2.8 interchangeably. ${ }^{25}$

- The proportion of delivery done by qualified doctors in Rajshahi was $22.1 \%$ which was lowest compared with other divisions. ${ }^{8}$

- The percentage of delivery held in a facility centre in Rajshahi was 13.2 whereas that in Khulna and Dhaka was 22.4 and 16.9 respectively. ${ }^{26}$

- The percentage of mothers with at least one ante-natal care (ANC) visit in Rajshahi was 71.3 while the figure for Khulana and Rangpur was 77 each. ${ }^{8}$

- Around $60 \%$ of mothers in Rajshahi division had less or least access to ANC provided by medical personnel whereas only half of mothers in Khulna division had less or least access. ${ }^{27}$

\section{Site selection}

The Rajshahi City, one of the largest cities in the northern region, was targeted to study. The area was then chosen by using the 'multistage sampling' method. Reproductive aged women, living in remotest areas and disadvantaged position, were main sources of information relating to access barriers. Zianagar and Baze Kazla are two remotest areas in Rajshahi City where poor people live in. ${ }^{28}$ The main target of the research was to interview slum dwellers. One hundred respondents from each area were targeted to be interviewed.

The study site
i. Zianagar
Bulanpur is in the $4^{\text {th }}$ Ward of Rajshahi City

Corporation. This ward consists of five areas (Nowabgong, keshabpur, Ghoshpara, Haragram and Zianagar). The selected area (Zianagar) is 1.5 kilo meter on the east-west and 1 kilo meter on the north-south. Many NGOs, particularly ASA, BRAC, Grameen Bank, CSS and Tilottoma, are operating their activities in this area. Most of the people here have been involved in micro-credit programs, do not have agricultural lands and are day labourers. As it is a border area, few people earn money from smuggling goods. As observed, most of the people had less access to safe drinking water because of their full reliance on supply water which was fully electricity based. Total number of households was 820 as per ward counsellor's office information.

\section{ii. Baze Kazla}

Baze kazla belongs to Ward no 24 in Rajshahi City Corporation. This place is nearby Padma River which is now turned into a char land area. It is one of the densely populated areas in Rajshahi City. As observed, sanitation facility was not adequate. So they lived in a dirty and filthy environment which was a threat to their health. They did not have nearby medical service delivery centre. They travelled long distance for getting a healthcare service delivery centre. There were 390 households in this area.

\section{Development of research instrument}

With some addition and correction of an initially developed draft interview schedule, a semi-structured interview schedule (including both open and close ended questions) was finalized for pre-testing. One-day long intensive training was given to research assistants (RAs) with objectives of giving them orientation about issues to be studied and how interview schedule should be filled up. Getting feedbacks from the pre-testing, necessary correction and modifications were made in the interview schedule. It was then ready for conducting interviews among recipients of MHC services.

Once the interview schedule was finalised after the pre-testing, RAs prepared themselves for conducting interviews. Field investigation began in early March and ended in early April 2013. One street from selected areas was chosen randomly. Then a married woman was randomly picked up for interview. Based on her knowledge regarding the availability of nearby mothers/ women with pregnancies/babies, the consecutive respondents were selected (by using snowball sampling technique). It should be mentioned here that RAs were instructed that they should interview mothers from different clusters and avoid the next door neighbour of the interviewee. The basic principle for giving this instruction is to collect information from heterogeneous respondents, albeit they are homogenous in basic socioeconomic parameters, thereby maintaining quality of the study. One hundred females from each area were interviewed. On an average, time required for interviewing females is 45 minutes. The total number of respondent is 200 .

Once interviews of females were over, a check was made where respondents invariably went for MHC services. Heads of these healthcare centres be it formal organisation or local pharmacy were targeted to interview. The total number of interviews conducted is nine. Out of nine, only three are organizational heads. As most of the respondents initially went to their local 
doctors, who were basically drug peddlers and had minimum level of medical training, for treatment, this fact stimulated us for interviewing them.

Five FGDs were held. Three were done with service recipients and two with service providers of the NGO health centre. The head of organization and friendly respondents were used as gate keepers for arranging meetings. The date and time for FGD was fixed with their consent. Three FGDs (one with service provider and two with clients) were done in Baze Kazla and two (one with service recipients and providers each) in Zianagar. The main aim of doing FGD was to find out what types of barriers service recipients faced during the use of healthcare services and service providers encountered when they provided services. How all these barriers could be mitigated was another objective of conducting FGDs. Each FGD lasted for two hours. Each group consists of six people.

After completing the field investigation, all the interview schedules were edited and some errors were detected and corrected accordingly. All data was coded and analyzed through the Statistical Package for Social Sciences (SPSS) program. Then it was presented in a tabular form. Comments made by service providers and FGD participants were quoted in the text. This study got ethical permission from the National Academy for Planning and Development (NAPD), Dhaka for doing this research.

\section{Results}

Socio-demographic profiles of the respondents

As Table 1 revealed, more than half of the respondents were below 25 years old and almost all of them were married. Forty-six percent respondents had secondary level of education which is followed by respondents with primary level of education (31.5) and respondents without formal education (13.5). Six in ten respondents had families with four to six members whereas three in ten had three-member based families. Slightly over half of the respondents had sanitary latrines and the rest had kutchcha type of latrine. This figure is as same as the national figure $-56 \%$ people have sanitation facilities at present. ${ }^{29}$ That means, the study area is not fully covered by sanitary facilities. Six in ten respondents had access to safe drinking water (tube well or pump) which is really good for keeping health free from water-borne disease.

Most of the respondents (85\%) were unemployed (Table 2 ) - they were not economically empowered and fully dependent on incomes of their family male members, particularly husbands. A half of the respondents had monthly family income from 5000 to 10000 Taka which is followed by respondents with below $5000(31 \%)$ and over 10,000 (11\%) Taka income. Seventy-seven percent respondents had their own houses. However, slightly over half of respondents lived in a single room. That indicates that they live in a congested environment which does not ensure their privacy and is prone to spread diseases. Almost all respondents lived in a house with tin roof. Forty percent respondents had walls with brick/cement or hemp/hay/bamboo each. Nearly half of the respondents had electricity, fan, clock and television. Almost all respondents (nine in ten) had mobile and khat (a wood-made bed).
Around $31 \%$ respondents lived below the US\$2 poverty line as per Table 2 . If poverty is multidimensionally measured, around $40 \%$ respondents were deprived of a decent living standard. According to a study. ${ }^{30}$ one household can be rated as deprived if its members have not finished five years of schooling and have no access to electricity; it has dirt, sand or dung floor; and it does not own more than one consumer goods. In light of the above given study, a half of the respondents lived below the multidimensionally determined poverty line.

\section{Barriers to access to maternal healthcare services}

The whole range of access barriers can be divided into four broad sections, such as socio-cultural, physical, financial and organizational. Here, the results of the study are highlighted in the light of the above given division of access barriers.

\section{i. Socio-cultural barrier}

\section{Patriarchal social norm and early marriage}

Bangladesh is a traditional and patriarchal society where women mainly have limited freedom to move outside of household and to take decision about reproductive health independently. This patriarchal

Table 1: Socio-demographic profiles of respondents

\begin{tabular}{|c|c|}
\hline Different categories & Frequency \\
\hline \multicolumn{2}{|l|}{ Age } \\
\hline $14-19$ & $49(24.5 \%)$ \\
\hline $20-25$ & $86(43 \%)$ \\
\hline $26-31$ & $50(25 \%)$ \\
\hline $32-37$ & $12(6 \%)$ \\
\hline $38-43$ & $3(1.5 \%)$ \\
\hline Total & $200(100 \%)$ \\
\hline \multicolumn{2}{|l|}{ Marital status } \\
\hline Married & $198(99 \%)$ \\
\hline Divorcee & $2(1 \%)$ \\
\hline Total & $200(100 \%)$ \\
\hline \multicolumn{2}{|l|}{ Educational qualification } \\
\hline No education & $27(13.5 \%)$ \\
\hline Primary & $63(31.5 \%)$ \\
\hline Secondary & $92(46 \%)$ \\
\hline Higher secondary & $4(2 \%)$ \\
\hline Can write \& read & $13(6.5 \%)$ \\
\hline No response & $1(0.5 \%)$ \\
\hline Total & $200(100 \%)$ \\
\hline \multicolumn{2}{|l|}{ Number of family members } \\
\hline $1-3$ & $56(28 \%)$ \\
\hline $4-6$ & $119(59.5 \%)$ \\
\hline $7-9$ & $21(10.5 \%)$ \\
\hline $10-12$ & $3(1.5 \%)$ \\
\hline $13-15$ & $1(0.5 \%)$ \\
\hline Total & $200(100 \%)$ \\
\hline \multicolumn{2}{|l|}{ Types of latrine } \\
\hline Sanitary/water sealed/pit & $104(52 \%)$ \\
\hline Kutchcha & $93(46.5 \%)$ \\
\hline Bush & $1(0.5 \%)$ \\
\hline Open space & $1(0.5 \%)$ \\
\hline Other & $1(0.5 \%)$ \\
\hline Total & $200(100 \%)$ \\
\hline \multicolumn{2}{|l|}{ Sources of drinking water* } \\
\hline Tap & $96(48 \%)$ \\
\hline Tube well/pump & $120(60 \%)$ \\
\hline
\end{tabular}


Table 2: Socio-economic characteristics of respondents

\begin{tabular}{|c|c|}
\hline Different characteristics & Respondents (\%) \\
\hline \multicolumn{2}{|l|}{ Occupation } \\
\hline Service & $2(1 \%)$ \\
\hline Business & $2(1 \%)$ \\
\hline Non-agricultural labourer & $4(2 \%)$ \\
\hline Household worker & $6(3 \%)$ \\
\hline Self-employed & $11(5.5 \%)$ \\
\hline Student & $2(1 \%)$ \\
\hline Unemployed & $170(85 \%)$ \\
\hline Others & $3(1.5 \%)$ \\
\hline Total & $200(100 \%)$ \\
\hline \multicolumn{2}{|c|}{ Income level (family and monthly) } \\
\hline $1-5000$ & $62(31 \%)$ \\
\hline $5001-10000$ & $105(52.5 \%)$ \\
\hline $10001-15000$ & $22(11 \%)$ \\
\hline $15001-$ & $11(5.5 \%)$ \\
\hline Total & $200(100 \%)$ \\
\hline \multicolumn{2}{|l|}{ Ownership of the house } \\
\hline Yes & $154(77 \%)$ \\
\hline No & $46(23 \%)$ \\
\hline Total & $200(100 \%)$ \\
\hline \multicolumn{2}{|l|}{ Number of living rooms } \\
\hline 1 & $107(54.3 \%)$ \\
\hline 2 & $55(27.9 \%)$ \\
\hline 3 & $28(14.2 \%)$ \\
\hline 4 & $5(2.5 \%)$ \\
\hline 5 & $2(1 \%)$ \\
\hline Total & $197(100 \%)$ \\
\hline No response & 3 \\
\hline \multicolumn{2}{|l|}{ Types of roof } \\
\hline Cement & $5(2.5 \%)$ \\
\hline Tin/wood & $190(95.5 \%)$ \\
\hline Tile/wood & $2(1 \%)$ \\
\hline Other & $2(1 \%)$ \\
\hline Total & $199(100 \%)$ \\
\hline No response & 1 \\
\hline \multicolumn{2}{|l|}{ Types of wall } \\
\hline Brick/cement & $80(40 \%)$ \\
\hline CI sheet/wood & $2(1 \%)$ \\
\hline Mud brick & $11(5.5 \%)$ \\
\hline Hemp/hay/bamboo & $83(41.5 \%)$ \\
\hline Other & $24(12 \%)$ \\
\hline Total & $200(100 \%)$ \\
\hline \multicolumn{2}{|l|}{ Types of consumer goods } \\
\hline Electricity & $98(49 \%)$ \\
\hline Mobile & $175(87.5 \%)$ \\
\hline Refrigerator & $7(3.5 \%)$ \\
\hline Fan & $93(46.5 \%)$ \\
\hline Clock & $99(49.5 \%)$ \\
\hline Television & $88(44 \%)$ \\
\hline Almira & $38(19 \%)$ \\
\hline Khat & $178(89 \%)$ \\
\hline
\end{tabular}

and traditional mentality creates a barrier for women to receiving MHC services. The study found (Table 3 ) that more than half of the respondents had less control over resources. Their husbands were main controllers of all household resources. This indicates that the study women were economically not empowered suggesting that they naturally had few opportunities in making decision about seeking reproductive healthcare services.

However, a significant number of decision makers about receiving MHC services in an urgent situation were both husband and wife (Table 4). The number of husbands (56) making decision solely about reproductive health
Table 3: Who controls family resources?

\begin{tabular}{|l|c|}
\hline Types of people & Respondents (\%) \\
\hline Self & $43(21.6 \%)$ \\
\hline Husband & $115(57.8 \%)$ \\
\hline Mother-in-law & $15(7.5 \%)$ \\
\hline Father-in-law & $11(5.6 \%)$ \\
\hline Other & $15(7.5 \%)$ \\
\hline Total & $199(100 \%)$ \\
\hline
\end{tabular}

treatment was doubled as many as the number of females (28) making self decision. Likewise, as indicated in Table 5, 67.5\% women had a lesser amount of freedom to go outside. That means, the permission for going outside for treatment comes from male household heads. Only $24 \%$ women had freedom for movement outside and only $8.5 \%$ enjoyed free movement rights.

A positive relationship between women's involvement in different organizations located outside home and receiving $\mathrm{MHC}$ services found in the literature. Only one hundred and seventeen women among two hundred were actively involved in activities of different organizations (Table 6). Almost all of them were involved in micro-credit activities. Only twenty eight reported that their organizations arranged

Table 4: Types of decision makers of reproductive health-related problems

\begin{tabular}{|l|c|}
\hline Types of people & Respondents (\%) \\
\hline Self & $28(14 \%)$ \\
\hline Husband & $56(28 \%)$ \\
\hline Both & $94(47 \%)$ \\
\hline Other & $22(11 \%)$ \\
\hline Total & $200(100 \%)$ \\
\hline
\end{tabular}

Table 5: Freedom to move anywhere

\begin{tabular}{|l|c|}
\hline Free movement & Respondents (\%) \\
\hline Yes & $48(24 \%)$ \\
\hline No & $135(67.5 \%)$ \\
\hline Sometimes & $17(8.5 \%)$ \\
\hline Total & $200(100 \%)$ \\
\hline
\end{tabular}

Table 6: Types of activities organisations per-

\begin{tabular}{|l|r|}
\hline Different issues & Respondents (\%) \\
\hline Organisational involvement & $117(58.5 \%)$ \\
\hline Yes & $83(41.5 \%)$ \\
\hline No & $200(100 \%)$ \\
\hline Total & $116(99 \%)$ \\
\hline Types of program performed & $1(0.5 \%)$ \\
\hline Micro-credit & $1(0.5 \%)$ \\
\hline Health-related & $117(100 \%)$ \\
\hline Other & \\
\hline Total & $28(24 \%)$ \\
\hline Arranging meeting & $89(76 \%)$ \\
\hline Yes & $117(100 \%)$ \\
\hline No & $1(3.5 \%)$ \\
\hline Total & $14(50 \%)$ \\
\hline Types of information provided & $22(78.5 \%)$ \\
\hline Female empowerment & $14(50 \%)$ \\
\hline Maternal healthcare issue & $6(21 \%)$ \\
\hline Child health issue & 28 \\
\hline Immunization & \\
\hline Other & \\
\hline Total & \\
\hline
\end{tabular}


different types of meetings main focuses of which were child health (78.5\%), MHC (50\%), and immunizations $(50 \%)$.

Marriage at an early age is another reason for poor women that causes in disempowering them to talk about healthcare seeking behaviour. Early marriage is a prevalent factor in less educated and financially insolvent households. ${ }^{31-33}$ In this case, there is no exception. Most of the respondents got married at their earliest ages as they all had at least one baby. One girl, aged 13 years standing beside one FGD meeting place at Zianagar, had two-year old baby.

It has been reported in a daily newspaper that poverty, social insecurity and a trend to increase dowry with the rise in girl age push poor parents to give their daughters marriage at early age. ${ }^{33}$ The early married women get pregnant when they are not physically and mentally ready for this. Even in most cases, they have less financial and mental capabilities to reach a right decision about seeking healthcare at the proper time. This lack of physical, mental and financial capacities due to marriage at an early age pushes lives of both young mothers and their would-be born babies at greater risks.

\section{ii. Physical barrier}

\section{Distance}

Distance of healthcare service delivery centre and time to reach there are significant issues that can influence people decisions on going to centres for treatment. In this study, these two factors are positively influencing mothers' decisions for receiving treatment from nearest healthcare centres. Ninety-two percent respondents reported the availability of healthcare centres at their nearest places. Nearly half of respondents travelled one and more than three quarters travelled two kilo meters for reaching the nearest healthcare centre (Table 7). It indicates that distance from household to healthcare centre is not a significant barrier for mothers to avail MHC services.

Table 8 showed that more than three-fourth respondents reached their nearest centres by walking while only one

Table 7: Distance respondents travelled for healthcare

\begin{tabular}{|l|c|}
\hline Distance (Km) & Respondents (\%)* \\
\hline 0.50 & $8(4 \%)$ \\
\hline 1.00 & $84(42 \%)$ \\
\hline 2.00 & $65(32.5 \%)$ \\
\hline 3.00 & $31(15.5 \%)$ \\
\hline 4.00 & $7(3.5 \%)$ \\
\hline 5.00 & $2(1 \%)$ \\
\hline 6.00 & $1(0.5 \%)$ \\
\hline Total & $198(99 \%)$ \\
\hline
\end{tabular}

*Multiple responses

Table 8: Ways of travelling healthcare centre

\begin{tabular}{|l|c|}
\hline Different ways & Respondents (\%) \\
\hline Auto-rickshaw & $55(27.5 \%)$ \\
\hline Rickshaw & $37(18.5 \%)$ \\
\hline Boat & $1(0.5 \%)$ \\
\hline On foot & $153(76.5 \%)$ \\
\hline Other & $1(0.5 \%)$ \\
\hline
\end{tabular}

quarter used auto-rickshaw for the same purpose. Almost all respondents (97\%) reached from their households to healthcare centres within a half an hour (Table 9).

\section{Waiting time}

The perception of people about waiting time for starting treatment is one of the indicators which creates significant influence in making decision about seeking healthcare from a particular centre. The study found that treatment of $65 \%$ respondents and of $30 \%$ respondents started 30 minutes and 60 minutes later respectively (Table 10). This suggests that service providers initiated treatment after they were reached. However, in some cases, the waiting time might differ.

\section{iii. Opportunity costs}

People with less education and social status feel discomfort to go to hospital because of their unfamiliarity with hospital environment. They certainly search knowledgeble people of hospital environment who can give them time during their visits. Accompanied people can use time given to them for productive purposes. For this reason, people are nowadays unwilling to go to healthcare centres for others. The study also found the same pattern. Table 11 revealed that around $44.5 \%$ respondents travelled alone and $21 \%$ travelled with husbands for getting to healthcare centres. The next available accompanying persons were either parents or mother-in-laws. That means, near relatives give their time when patients wish to visit medical centre and stay there.

Costs relating to treatment and others sometimes deter poor households from seeking care of highly

Table 9: Time for reaching healthcare centre

\begin{tabular}{|c|c|}
\hline Time (minute) & Respondents (\%) \\
\hline $1-15$ & $94(47 \%)$ \\
\hline $16-30$ & $100(50 \%)$ \\
\hline $31-45$ & $0(0 \%)$ \\
\hline $46-60$ & $3(1.5 \%)$ \\
\hline Total & $197(98.5 \%)$ \\
\hline
\end{tabular}

Table 10: Waiting time for treatment

\begin{tabular}{|l|c|}
\hline Time (minute) & Respondents (\%) \\
\hline $1-15$ & $61(30.5 \%)$ \\
\hline $16-30$ & $69(34.5 \%)$ \\
\hline $31-45$ & $10(5 \%)$ \\
\hline $46-60$ & $60(30 \%)$ \\
\hline Total & $200(100 \%)$ \\
\hline
\end{tabular}

Table 11: Types of accompanying persons in healthcare centre

\begin{tabular}{|l|l|}
\hline Accompanying person & \multicolumn{1}{|c|}{ Respondents (\%) } \\
\hline Parents & $27(13.5 \%)$ \\
\hline Husband & $42(21 \%)$ \\
\hline Sister & $15(7.5 \%)$ \\
\hline Mother-in-law & $26(13 \%)$ \\
\hline Sister/brother-in-law & $25(12.5 \%)$ \\
\hline Neighbour & $7(3.5 \%)$ \\
\hline Health worker & $5(2.5 \%)$ \\
\hline None/self & $89(44.5 \%)$ \\
\hline Other & $11(5.5 \%)$ \\
\hline
\end{tabular}

*Multiple responses

South East Asia Journal of Public Health 2018;8(1):22-31 
sophisticated hospitals. As indicated in Table 12, only $40 \%$ respondents paid money for initial treatment of the nearest centres and the range of payment was from one to sixty Taka. That means, the centres they went for treatment charge very minimal amount of money.

Table 13 suggested that nearly three quarter respondents spent not more than 2000 Taka for the last treatment. Only $16.5 \%$ spent more than 5,000 Taka for the same purpose. The percentage of respondents borrowing money from relatives for bearing exorbitant costs of treatment was 18 (Table 14). It is important to mention here that, as found from the conversation with service providers, the cost of normal delivery in NGO centre was 1000 or 1200 Taka while that of Caesarean delivery was 8000 . Mariam, one FGD participant, mentioned that she needed more than 10,000 Taka for Caesarean baby delivery. This cost included no medicine costs. However, a poor woman delivered a baby normally at

Table 12: Money paid for visiting the centres

\begin{tabular}{|l|c|}
\hline Range of amount & Respondents (\%) \\
\hline $1-15$ & $35(17.5 \%)$ \\
\hline $16-30$ & $32(16 \%)$ \\
\hline $31-45$ & $8(4 \%)$ \\
\hline $45-60$ & $5(2.5 \%)$ \\
\hline Total & $80(40 \%)$ \\
\hline
\end{tabular}

Table 13: Treatment costs

\begin{tabular}{|l|c|}
\hline Range of money & Respondents (\%) \\
\hline $1-1000$ & $117(58.5 \%)$ \\
\hline $1001-2000$ & $30(15 \%)$ \\
\hline $2001-3000$ & $10(5 \%)$ \\
\hline $3001-4000$ & $7(3.5 \%)$ \\
\hline $4001-5000$ & $3(1.5 \%)$ \\
\hline $5000+$ & $33(16.5 \%)$ \\
\hline Total & $200(100 \%)$ \\
\hline
\end{tabular}

Table 14: Borrowed money and its related issues

\begin{tabular}{|l|r|}
\hline Different issues & \multicolumn{2}{|r|}{ Respondents (\%) } \\
\hline Self expenditure & $158(79 \%)$ \\
\hline Yes & $36(18 \%)$ \\
\hline No & $194(97 \%)$ \\
\hline Total & $36(100 \%)$ \\
\hline No response=6 & $3(8 \%)$ \\
\hline Types of sources $*$ & $2(5.5 \%)$ \\
\hline Relatives & $1(2.7 \%)$ \\
\hline Neighbour & $10(27.7 \%)$ \\
\hline Friends & 36 \\
\hline Money lender & \\
\hline NGOs & $13(36 \%)$ \\
\hline Total & $5(13.8 \%)$ \\
\hline Methods of repayment $*$ & $23(63.8 \%)$ \\
\hline Instalment & $7(19.4 \%)$ \\
\hline Extra work & 36 \\
\hline No need to repay & \\
\hline Other & $15(68 \%)$ \\
\hline Total & $4(18 \%)$ \\
\hline No of days needed for repayment & $3(13 \%)$ \\
\hline $1-30$ & 22 \\
\hline $31-90$ & \\
\hline $91-365$ & \\
\hline Total & \\
\hline
\end{tabular}

*Multiple responses free of costs. In contrast, half of the Caesarean delivery expenses were waived for poor women. A person with a LA (least advantage) card could receive medicine worthy 150 Taka free. He or she could receive free medicine four times in a month. This facility was available up to four members of a family and one year. Most borrowers repaid nothing as they borrowed money from their kins. Those who repaid used instalment method or did extra work. In most of the repayment cases, it took a month.

\section{iv. Organisational barrier}

\section{Gender dynamics}

Males were the main service providers in most centres we made visits. Naturally respondents hesitated to explain their problems to them due to social construction of mind. Most participants in FGDs complained that they could not express their physical problems to male doctors. When the condition became worse, they purchased medicine from local pharmacy showing paper on which symptoms were written.

\section{Quality of care}

The perception developed about quality of healthcare services sometimes influences people's decisions on taking care from any particular healthcare centre. The study found satisfaction of respondents about treatment quality of centres. Most respondents (92\%) had opportunities of talking with doctors about their problems (Table 15). nearly half of the respondents reported that they could talk about their problems from six to ten minutes whereas $33 \%$ talked up to five minutes. Nine in ten women were satisfied with treatment of centres visited and $96 \%$ expressed their opinion of revisiting these centres in need of future. However, only $30 \%$ reported that everything was clearly explained to them. That means, though most

Table 14: Quality of care of the centres visited

\begin{tabular}{|l|c|}
\hline Different criteria & Respondents (\%) \\
\hline Types of consultants & \\
\hline Doctor & $194(92 \%)$ \\
\hline Nurse & $25(12.5 \%)$ \\
\hline Health assistant & $18(9 \%)$ \\
\hline Consulting time (minute) \\
\hline $1-5$ & $66(33 \%)$ \\
\hline $6-10$ & $85(42.5 \%)$ \\
\hline $11-15$ & $20(10 \%)$ \\
\hline $16-20$ & $17(8.5 \%)$ \\
\hline $21-25$ & 0 \\
\hline $26-30$ & $11(5.5 \%)$ \\
\hline Total & $199(99.5 \%)$ \\
\hline Satisfaction & $180(90 \%)$ \\
\hline Yes & $19(9.5 \%)$ \\
\hline No & $199(99.5 \%)$ \\
\hline Total & $192(96 \%)$ \\
\hline Revisit in future & $5(2.5 \%)$ \\
\hline Yes & $197(98.5 \%)$ \\
\hline No & $60(30 \%)$ \\
\hline Total & $138(69 \%)$ \\
\hline Explaining issues & $198(99 \%)$ \\
\hline Yes & \\
\hline No & \\
\hline Total & \\
\hline Multiple responses & \\
\hline
\end{tabular}


respondents were satisfied with treatment quality, seven in ten were not happy with the doctors' seriousness of their physical problems. Lack of sufficient time of the service providers due to their huge involvement in the administrative work and non-development of culture of explaining everything to patients could be reasons for this dissatisfaction.

The overall quality of service centre can be improved further if genuine coordination is established among different organisations with the same bundle of healthcare services, thereby producing no inclusion or exclusion error in the project area. The study found lack of coordination among service providing organisations, therefore providing same services by different organisations in same area, as one of the prime organisational barriers to further improvement of health service quality.

\section{Lack of coordination and overlapping}

Almost all organizational centres visited had a provision of delivering 40 or $30 \%$ services at free of costs to poor. They introduced a card for administering this free service. The main criteria they used for identifying poor were level of income (not more than 2000 Taka), widow or divorcee, landless and household size. They distributed the card for free services in 2003. Ten years later criteria were revised. The consultation made with service providers and opinion expressed during FGD hinted that they were not sure about criteria of measuring free services. They opined that they provided services full free in a whole day. Even in some cases, patients bargained for free services and they also provided free services. The lack of clear-cut criteria about free services and of a clear definition of the poor was one of the main reasons for generating low amount of revenues. For instance, one centre reported that they earned only 20,000 Taka against 100,000 (total costs of the centre) last month.

A few number of good service delivery organizations were available in study areas. People had more than one card for receiving free services from different organizations. Resultantly, patients took same medicine from different organizations that might cause physical problems in their bodies. Most organizations set target for field workers (FWs). This target exerted pressures on FWs for dispensing medicine among people who received same service from other organizations. In some cases, FWs crossed their catchment areas for fulfilling the target.

Doctors in NGO centres were less attentive to patients and efficient in service delivery. An experienced doctor showed unwillingness to dispense services result of insecurity in job. Therefore, centres had no alternative options rather recruiting a newly graduated doctor. This insecurity in job pushed newly appointed doctors to involve in other activities, such as giving time to get a permanent job, which diverted their time from delivering services attentively. In some cases, doctors left organizations after providing services for two years. If doctors are well-mannered and reputed, people naturally seek them during their next visits. The absence of the same doctor in healthcare centre was one of the main reasons for which mothers hesitated to go there again for further treatment.

\section{Discussion}

Physical and financial barriers are less acute than socio - cultural barrier

Girls' marriage at early age is prevalent in Bangladesh. ${ }^{34-39}$ This causes pregnancy at an earlier life of their reproductive span. Women getting pregnant at early age may face many complications compared with women being pregnant at matured age. Less access to safe drinking water and to sanitary latrines, and congested living room resultantly hampering privacy, may jeopardize their complications. All these complications may push their lives at greater risks. In addition, patriarchal social norm disempowers women physically, mentally and financially. These women lastly fail to go outside for different purposes, particularly receiving treatment from outside doctors. This argument has been corroborated by other studies. ${ }^{38-}$

The Government of Bangladesh has taken many initiatives for reaching people's doorsteps with healthcare services since independence. ${ }^{45-48}$ Other private and NGOs have also been trying to provide healthcare services at people's convenient places. All these endeavours have resulted in building healthcare service delivery centres and providing healthcare services at people's doorsteps. Three-fourth respondents have healthcare centres (within two kilometres radius) where they can reach on foot in a half an hour. As many organisations are available for providing services on a competitive basis, they always like to keep patients less waiting for treatment. Waiting time found in most cases is maximum a half an hour.

Most women in study areas receive free treatment. They spend money for convenience or drugs. It is important to mention here that they receive drugs in subsidised prices. In complicated situations, here the need for caesarean delivery, it is necessary for mothers and their families to manage huge amounts of money, although the number of such cases was insignificant $(1.5 \%)$. When needed, they usually borrow money from either relatives or micro credit organisations/money-lenders. Customarily, money borrowed from relatives need not to be repaid. It seems that physical and financial barriers do not create hindrances to making decisions for receiving $\mathrm{MHC}$ services.

\section{Organisational barriers are keen}

Most of the centres in study areas have male doctors to whom respondents feel shy talking about their physical conditions. This shyness is socially and culturally constructed. They were forced to open their mouths when they found that their physical conditions were at high risks. Almost all centres visited during the study period had a provision of dispensing $30 \%$ or $40 \%$ services free to poor. Inconsistencies in definitions of poor family of different orgnizations resulted in generating exclusion or inclusion error in the project. In addition, poor family had more than one card which ensured free treatment and subsidized medicine to a limited extent. Consequently, poor family had same services and treatment at free of costs from different organizations at a time. These two factors (more than one card in each poor family and crossing the catchment areas result of fulfilling targets set by organizations) 
caused in overuse of free medicine. Realizing this issue at the field level, all experts in a roundtable discussion urged for strengthening the coordination between government and NGOs in order to meet the reproductive health-related target, including the reduction of high maternal deaths. ${ }^{49}$

As most organizations are project based, experienced doctors are usually unwilling to serve there with due attention. Even if some experienced doctors join there, they always want to discontinue their jobs once they find any suitable and permanent jobs. Their sudden leave from organizations results of availing suitable and permanent jobs hampers continuation of organizational activities that jeopardizes poor mothers' access to MHC services. A plethora of studies ${ }^{17-19,50}$ also identify organizational barriers, such as lack of good quality services, unavailability of service providers, untimely response from healthcare providers, that detract women, in particular poor, from receiving due service at due time.

\section{Conclusion}

Girls are getting married at their early ages because of social customs and norms. This causes women getting pregnant earlier that create their lives at greater risks. Less access to safe drinking water and to sanitary latrines and living in a dirty environment also aggravate their risks. As most services of different organizations — providing free treatment and subsidized drugs for the poor to a limited extent - are readily available, physical and financial factors seem not to affect poor household's decision about seeking care from their nearest centres. However, the lack of a clear-cut definition of the poor creating troubles in fulfilling target thereby causing in/exclusion errors in the project, absence of doctors in service centres owing to sudden leave, overlapping service delivery (providing same services by different organizations in same area at a time) and lack of coordination among different organizations about catchment areas resulting in over use of free healthcare services, including medicine, are the prime factors that hamper further improvement of $\mathrm{MH}$ in study areas. The study therefore suggests the following recommendations for further improvement of $\mathrm{MH}$ in urban areas.

- Building awareness of bad consequences of early marriage on $\mathrm{MH}$ through mobilization of community and using print and electronic media.

- There should be coordination about free healthcare services. The government should fix one centre which provides free services in a particular area. So that over use of free services can be stopped.

- Female doctors should be encouraged to work for poor.

- Developing a method how to retain doctors in the project areas for a longer time.

\section{Competing interest}

The authors declared that there is no conflict of interest.

\section{Funding}

Funding received from the National Academy of Planning and Development (NAPD), Dhaka, Bangladesh.

\section{Acknowledgement}

The paper is a part of the report of the research project-Barriers to Access Maternal Health Care Services among Urban Poor Women in Bangladesh: A Case of Rajshahi City-financed by the National Academy for Planning and Development (NAPD), Dhaka, Bangladesh.

\section{References}

1. Ahmed S, Khan M. A maternal health voucher scheme: What have we learned from the demand -side financing scheme in Bangladesh. Health Policy Plan 2011;26(1):25-32.

2. Anderson P. After Nehru. London Review of Books 2012; 34: 21-36.

3. Deshe pusti paristhitir unnati janmanintran karjakom sthabir (Improvement in nutrition but stallation in famiy planning program in Bangladesh) Prothom Alo. April 26, 2015.

4. Uddin MA, Rahman ML. Stalling of Human Fertility in Bangladesh: Causes and Consequences. CDRJ 2006; 1(2): 133-140.

5. Nath Dk. Health policy for achieving MDGs, Point Counterpoint, The Daily Star. April 21, 2008.

6. ESCAP Population Data Sheet 2007. Bangkok: Population Division of United Nations, 2007.

7. United Nations Development Program. Human Development Report 2003. New York: UNDP, 2003.

8. National Institute of Population Research and Training . Bangladesh Demographic and Health Survey, 2011: Preliminay Report. Dhaka, Bangladesh and Calverton, Maryland, USA: National Institute of Population Research and Training, Mitra and Associates, and Macro International, 2012.

9. Central Intelligence Agency (CIA). The World Factbook. South Asia: Bangladesh 2013. https:// www.cia.gov/library/publications/the-worldfactbook/geos/bg.html (accessed Dec 2018).

10. Borghi J, Hanson K, Acquah C, Ekanmian G, Filippi V, Ronsmans C, et al. Costs of near-miss obstetric complications for women and their families in Benin and Ghana. Health Policy Plan 2003;18(4):383-90.

11. D'Ambruoso L, Abbey M, Hussein J. Please understand when I cry out in pain: women's accounts of maternity services during labour and delivery in Ghana. BMC Public Health 2005;5 (1): 140 .

12. Fraser A. Approaches to reducing maternal mortality: Oxfam and the MDGs. Gender Dev 
2005; 13(1): 36-43.

13. 13. Hatt L, Stanton C, Makowiecka K, Adisasmita A, Achadi E, Ronsmans C. Did the strategy of skilled attendance at birth reach the poor in Indonesia? Bull World Health Organ 2007;85:774-82.

14. Johnson C. The Political Complexities of Safe Motherhood. Paper presented at the the Annual Meeting of the American Political Science Association, Toronto, 2009.

15. Koblinsky M, Matthews Z, Hussein J, Mavalankar D, Mridha M, Anwar I, et al. Going to scale with professional skilled care. Lancet 2006; 368(9544):1377-86.

16. Krupp K, Madhivanan P. Leveraging human capital to reduce maternal mortality in India: enhanced public health system or public-private partnership? Hum Resour Health 2009;7(1):18.

17. Maclean GD. Dimension, Dynamics and Diversity A 3D Approach to Appraising Global Maternal and Neonatal Health Initiatives. Trend Midwifery Res 2005: 261.

18. Miller S, Sloan N, Winikoff B, Langer A, Fikree $\mathrm{F}$. Where is the "E" in $\mathrm{MCH}$ ? The need for an evidence-based approach in safe motherhood. $J$ Midwifery Womens Health 2003;48(1):10-8.

19. Ogujuyigbe P, Liasu A. Perception and healthseeking behaviour of Nigerian women about pregnancy-related risks: strategies for improvement. J Chinese Clin Med 2007; 2(11): 643-54.

20. Parkhurst J, Penn-Kekana L, Blaauw D, Balabanova D, Danishevski K, Rahman S, et al. Health systems factors influencing maternal health services: a four-country comparison. Health Policy 2005; 73(2): 127-138.

21. Ronsmans C, Scott S, Qomariyah S, Achadi E, Braunholtz D, Marshall $\mathrm{T}$, et al. Professional assistance during birth and maternal mortality in two Indonesian districts. Bull World Health Organ 2009; 87: 416-423.

22. Suwal J. Maternal mortality in Nepal: Unraveling the complexity. Can Stud Popul 2008;35(1): 1-26.

23. Marshall AA, McKeon JK. Reaching the "Unreachables": Educating and Motivating Women Living in Poverty. In E. B. Ray (Ed.). Communication and Disenfranchisement. NJ: Lawrence Erlbaum Associates, 1996.

24. Germov J.Imagining Health problems as Social Issues. in: Second Opinion: An Introduction to Health Sociology. Germov, J (ed.). $4^{\text {th }}$ edition. South Melbourne, Victoria: Oxford University Press, 2009.

25. Bangladesh Institute of Development Studies (BIDS). Micro Impacts of Macroeconomic and Adjustment Policies in Bangladesh (MIMAP) 2003. Technical Paper no 8. Dhaka: BIDS, 2003.

26. National Institute of Population Research and
Training . Bangladesh Demographic and Health Survey, 2007. Dhaka, Bangladesh and Calverton, Maryland, USA: National Institute of Population Research and Training, Mitra and Associates, and Macro International, 2009.

27. National Institute of Population Research and Training . Bangladesh Demographic and Health Survey, 1999-2000. Dhaka, Bangladesh and Calverton, Maryland, USA: National Institute of Population Research and Training, Mitra and Associates, and Macro International, 2001.

28. Rajshahi City Corporation. Basic Service in Urban Area Project 2004. Rajshahi: RCC, 2004.

29. Samajik suchake varter cheye agiye Bangladesh (Bangladesh ahead India in social index) Prothom Alo. October 20, 2014.

30. Alkire S, Santos ME. Multidimesional Poverty Index. OPHI Research Brief 2010;1-8.

31. Cairo sommeloner bish bochhar o bangladesher projanonswasthya (20 years of Cairo Conference and Reproductive health in Bangldesh) Prothom Alo. September 15, 2014.

32. Aar noy matremetru (No more maternal deaths) Prothom Alo. October 20, 2014.

33. Jader thekanor dayitwa tarae modod dichchhen (encouraging people by responsible persons) Prothom Alo. May 4, 2015.

34. Bangladeshe balybibah berechhe (Increasing child marriage in Bangladesh). Prothom-Alo. March 7, 2018.

35. Yount KM, Crandall A, Cheong YF, Osypuk TL, Bates LM, Naved RT, Schuler SR. Child marriage and intimate partner violence in rural Bangladesh: a longitudinal multilevel analysis. Demograph 2016 Dec 1; 53(6): 1821-52.

36. Hossain MG, Mahumud RA, Saw A. Prevalence of child marriage among Bangladeshi women and trend of change over time. $J$ Biosoc $\mathrm{Sci}$ 2016;48(4):530-8.

37. Hackett KM, Mukta US, Jalal CS, Sellen DW. A qualitative study exploring perceived barriers to infant feeding and caregiving among adolescent girls and young women in rural Bangladesh. BMC Public Health 2015;15(1):771-81.

38. Alauddin M. Maternal mortality in rural Bangladesh: the Tangail District. Stud Family plann 1986;17(1):13-21.

39. Fall $\mathrm{CH}$, Sachdev HS, Osmond C, Restrepo-Mendez MC, Victora C, Martorell R, Stein AD, Sinha S, Tandon N, Adair L, Bas I. Association between maternal age at childbirth and child and adult outcomes in the offspring: a prospective study in five low-income and middle -income countries (COHORTS collaboration). Lancet Glob Health 2015;3(7): e366-77.

40. Islam A, Islam N, Bharati P, Aik S, Hossain G. Socio-economic and demographic factors influencing nutritional status among early childbearing young mothers in Bangladesh.

South East Asia Journal of Public Health 2018;8(1):22-31 
BMC Womens Health 2016;16(1):58-66.

41. Kamal SM, Hassan CH. Child marriage and its association with adverse reproductive outcomes for women in Bangladesh. Asia Pac J Public Health 2015;27(2):NP1492-506.

42. Kile ML, Rodrigues EG, Mazumdar M, Dobson CB, Diao N, Golam M, Quamruzzaman Q, Rahman M, Christiani DC. A prospective cohort study of the association between drinking water arsenic exposure and self-reported maternal health symptoms during pregnancy in Bangladesh. Environ Health 2014;13(1):29-39.

43. Campbell OM, Benova L, Gon G, Afsana K, Cumming O. Getting the basic rights-the role of water, sanitation and hygiene in maternal and reproductive health: a conceptual framework. Trop Med Int Health 2015;20(3):252-67.

44. Akseer N, Kamali M, Arifeen SE, Malik A, Bhatti Z, Thacker N, Maksey M, D'Silva H, da Silva IC, Bhutta ZA. Progress in maternal and child health: how has South Asia fared? $B M J$ 2017;357:j1608.
45. Khan R, Vandelaer J, Yakubu A, Raza AA, Zulu F. Maternal and neonatal tetanus elimination: from protecting women and newborns to protecting all. Int $J$ Womens Health 2015;7:17180 .

46. Haider MR, Rahman MM, Moinuddin M, Rahman AE, Ahmed S, Khan MM. Impact of maternal and neonatal health initiatives on inequity in maternal health care utilization in Bangladesh. PLOS One 2017; 12(7):1-15.

47. Sarwar MR. Bangladesh Health Service Delivery: Innovative NGO and Private Sector Partnerships. IDS Bull 2015; 46(3):17-28.

48. Kumar S, Bano S. Comparison and Analysis of Health Care Delivery Systems: Pakistan versus Bangladesh. J Hosp Med Manag 2017;3(1):1-7.

49. Prajanonswashya khater lakhymatra arjone samnway barate habe (Need to strengthen coordination to achieve the target in the reproductive health sector) Prothom Alo. August 14, 2014.

50. Chapman R. Endangering safe motherhood in Mozambique: prenatal care as pregnancy risk. Soc Sci Med 2003; 57(2): 355-374. 